\title{
ABOUT THE CONNECTION CONCERNING THE PROCESSES OF TRANSFORMATION IN ASIA IN THE SECOND PART OF THE XIX c. - FIRST PART OF THE XX c. AND THE ASIAN ECONOMICAL CRISIS IN THE END OF 1990s
}

\author{
Vladimir Ruvinskiy \\ Facultadde Hitmanidades, Universidad del Valle, AA 25360, Santiago \\ de Cali, Colombia e-mail: vladruv@geocities.com
}

\begin{abstract}
.
The second part of the XIX - first part of XX cc. are characterized as the period of the beginning of cardinal transformations in economical and social organization of East Asian society. These transformations are processes of economy reorganization and adaptation to the new circumstances as well as structural changes in East Asian public institutions caused by European expansion. The Asian economical crisis in the end of 1990s allows us to understand that the processes are not over yet and East Asia is still in the transformation.

The recent events in East Asia, especially the Asian economical crisis, are forcing more and more researchers to place their attention in the contemporary history of East Asia as a whole as well as to study some particular processes of long-term development such as problems of economical growth [13, 14], evolution of public institutions [9, 10,11, and 15] and production structures [2], market cycles [9] and some others include study of human development as a Homo Economicus $[3,8]$. In order to explain the modern events and problems within the frames of economical history researchers are elucidate how the economy and the society were organized and how they were functioning in one or another moment of development. From our point of view, one of the fundamental reasons of current Asian economical difficulties is lying in the processes of East Asian transformation towards a market economy, in the development of interrelationships between different countries and regions, world market formation and tremendous changes in the state and social organization which characterize the new Asian State. But when does this new East Asia starts? Where is the frontier between so called traditional East Asia and the new stage of East Asian development?

In the Marxist historiography there is a sharp border between the period
\end{abstract}


before and the period of the Modern History, or "New Era", itself [1], this period begins with one of the bourgeois revolutions in Europe and ends in 1917 with the October Revolution in Russia. History of all countries in the world is divided automatically in accordance with European History and not necessary in accordance with the real events and with the real dynamic impact of the historical process in the other regions. Meanwhile, even though in some cases the "Europe-oriented" method is suitable for other parts of the world, in East Asia this approach seems to be inappropriate. On the other hand, the division into periods as a method of interpretation and understanding of the historical events is important first of all because it gives us the possibility to see the development process in consistency. In East Asia the XIX century might be characterized as the century of the colonial expansion of industrial capitalism. This time the stream of different goods from Europe was quickly transforming this region into a valued market as well as an important source of the resources for European capitalism. This process was connected with the bankruptcy of the traditional East Asian industries, with the crisis of traditional East Asian trade, with the destruction of the traditional Asian way of life, with political instability and with the decreasing of the state influence. All these are real important new changes in East Asia, which gives us the right to mark the beginning of the new period of East Asian history and, correspondingly, the beginning of the processes of transformation which are interesting for us, by the middle of the XIX century.

What are the types of transformation processes we are talking about? First of all, there is the process of transformation of the traditional East Asian State organization under the influence of Colonialism. Then, there is integrally connected with the first one the process of transformation of the traditional East Asian economical organization. It is important to mention, that Colonialism here means the process of the formation of administratively autonomous enclaves on the external territories which were copying the metropolis by their internal structure, were very closely connected with the metropolis and which were strongly supported by it. No doubts that such colonies were possible to appear only when the market activity based on the private property was supported by the State. Those colonies were a basement for global Colonization, and the connection of the Colonialism with the genesis of European capitalism is very clear. The foundation on the Asian continent during the XVII and the XVIII centuries were such organizations as Sot-Indian companies which were trade companies of the capitalist character with the administrative rights, demonstrated that this was the period of active strengthening of the European colonial 
trade and earning of profits for young European capitalism. Thus, Colonialism in Asia had started with the colonial trade and continued long enough. Many things have changed during this process. Europe has changed. The profits and the foundation of the market economy played their role in the acceleration of European economical development. More market capacity and more turnovers, including the colonial trade turnover, were urgently needed in consequence of it.

Some researchers consider that in the XVI-XVIII centuries most parts of Asia already were in the process of the capitalist genesis and only slightly behind Europe. From their point of view, development of Japan is the ultimate confirmation for this thesis. But is it so obvious?

We don't have authentic statistical data for this period of Asian history. At the same time, there cannot be any doubt that Asia as a whole was not poorer than Europe. Moreover, Asian countries were able to produce more aliments than Europe while most of the local population in Asia was poorer than Europeans. Why Asians didn't use their richness for the fast development of capitalism?

Let's consider that the answer to this question is the following. In East Asia of that time, there were no conditions for capitalism as a completely different system of economic organization, which rejects traditional for East Asia domination of the State and holds the alternative of the private property and the free market. However, strong economical and, later, combined economical-political pressure, including direct military actions, played the key role in East Asian destiny during the period of Colonialism. Every East Asian country became involved into the process of the world market forming and started to transform internally. The mode of production, the volume of manufacture and connected with it labor skills, the way of life for the most part of urban population, moral values, including human attitude to Society, the Nature, to the World itself has changed. But how was traditional culture reacting to these changes? How was it combining its own elements with alien structural elements, elements of European tradition, without which the colonial capital in East Asia wouldn't function properly?

The difference between European and East Asian traditional economics, both of which does include the private sector, is in hierarchy of the typical connections inside the structure. For Europe those typical connections are market relations, which unite the main elements of the structure -proprietor and producer, free man and dependants, society and state, with the presence of the 
Rights, the Freedoms and the Guarantees as a fundament of these conditions. There are, of course, other connections: family, clan, estates, etc. But, generally, in Europe the first place is for marketable relations, all others are behind.

Asia was an absolute difference. Any market relations here were secondary and minor. The first place here was reserved for the relations that were mediated by State, i.e. by the system of centralized distribution. There were the traditional typical relations between social lower class, or producers, and upper class. Secondly important types of relations in East Asia were corporate relations, which force is sensitive during all the historical process up to modern times. In East Asia, the Authorities held the property and it was an alternative to the private property in Europe. All-powerful State was subject to the democracy, the rights and the freedoms. People were living here without knowledge of freedoms and guarantees of European character but on norms of the customary law. They were also united to the social corporations, which disowned any individual manifest. Of course, the private sector was also developing in East Asian countries but it was developing under control of the Authorities and out of the system of relations between the State and the Subject.

On the other hand, it would be incorrect to underestimate the role of the private economy in East Asia. A giant Asiatic self-regulating structure was always saving the private sector. There is no contradiction. From the point of the self-regulation of the structure it was necessary not to loose control over private economics otherwise the wave of private initiative might be followed by economical and social shock. At the same time, from the point of stability of developed sodium, saving of private activity closely connected with the market and marketable relations was also necessary because the private sector in Asia was helping the normal functioning of the giant social organism. An excessive activity of this sector would lead to a crisis or even downfall of the traditional structure, as it happened, for example, in the case of dynastic cycles in China, as well as an excessive slackening of the private sector might also lead to serious crisis and effects as it was in Mao's China with the attempt to abrogate marketable relations, or to form distorting off-economical distribution systems resembling the Soviet model.

Thus, in East Asia we can see its unique system of universally recognized values, which is very far from European standards. And the point is not in the attitude to the private property that supposed to be the first indication of the developed capitalism. The difference is wider. One (European) structure is oriented to the material benefits of an individual proprietor and another one (East 
Asian) is oriented to the corporate relations. This law of existence was the whole way of life in traditional East Asia but it still is very strong in new East Asia even after difficult transformations during the period of Colonialism.

When traditional East Asian structure started to interfere with the colonial capital it clashed with unknown individualistic behavior of a proprietor and began loosing its traditional power. First and natural reaction was the aspiration to adapt the new conditions of existence. But to do so it was necessary to make a revaluation of the habitual values comparing it with those brought by colonizers. European science and techniques, growing western life standard, constitutional rights, freedoms and guarantees, political pluralism altogether have made great influence to the East Asian upper class. At the same time, when East Asian upper class was adapting the achievements of modern Western civilization, a new sector of the economy was forming. This new pro-capitalist sector was closely connected with the world market and rapidly progressing. With the first appearance in the second part of the XIX c. and strengthening in the XX c. this sector of the economy was not exactly the same in China or in Japan but the principles of functioning were identical. The State was the general subject of the production system playing simultaneously the roles of entrepreneur and representative of the society, guarantying stability to the structure at whole. The risk of economical failure here was minimized but an averaged economic effectiveness of this sector was decreasing accordingly. A paradoxical situation appeared. The economical transformation was changing Asian society but the people did not understand and did not accept those changes. Later, it sets counteracts like in China where the Communist Party headed mass anti-market and anti-capitalist peasant movement.

Inside the traditional East Asian structure two parallel processes were going on: adaptation to the changed circumstances and resistance to thrusting changes. And the State was forced to form a necessary capitalist market infrastructure, i.e. to function as the Proprietor and the most important Subject of the economy. On the latest stage of colonial and post-colonial East Asia, the role of the State in economy not only doesn't reduce under the free market relation's influence but also even increased. In modern East Asian countries the State is still playing an important role on almost all parameters. As we already mentioned above, in such situations the risk of economical collapse is minimized but the ability to effectively react to the constantly changing world market situation is also reduced. Not surprisingly that inability to follow the changing world economical situation is named as one of the characteristics of the Asian economical 
crisis in the end of 1990 s.

The colonial capital gave to East Asia a strong impulse that not only aroused traditional East Asian structure but also added a new rhythm for forward development. At the same time, it is easy to see that the main elements of Western civilization are not only confronting the East Asian traditional elements but they are practically incompatible. On the one side, in Europe, there is material success of an individual protected by law and democratic procedures. From the other side, in East Asia, there are habitual norms of the all-powerful authorities and lack of rights for simple people, arbitrariness of the Powers that be, plus an individual, who is included for the purposes of the surviving into one or another social corporation which is organized internally on the principles of unconditional subordination of the younger before the older. Of course, since then East Asian societies have changed dramatically. The practice of the political struggle, political pluralism became an important element of the new East Asian political culture as well as universally recognized rights and the freedoms. Moreover, the educational breakthrough is considered as one of the main components of the East Asian economical miracle. But appearance of well-prepared people required for market economy doesn't change much their mentality based on the centuries-run tradition as well as does not affect strongly enough the traditional internal organization of the East Asian society. Something not only survived but even became stronger the previous. We are talking about corruption and bureaucracy, family and clan-patronized relations. The waves of corruption exposures, chronologically coincided with the current economical crisis, have attested that not only market laws are ruling economies in East Asia (see, for example, [6]). Still the important role belongs to family and clan-patronized relations, which are forming the economical skeleton in many parts of the continent.

At the same time, the continent of Asia was never homogeneous. There were always verges between advanced and flourishing countries from the one side, and backward regions from the other. But exactly nowadays the highest degree of the non-equivalent development is showing. These differences are the result of the successful start of internal transformations in some East Asian countries. For instance, the structure of Japan is Western (all techniques, technologies, science, education, and infrastructure) but its civilization is Asian. This organic merger, harmonically synthesized, was sine qua non of its forward development during the contemporary period of Asian history. But some elements of the Japanese symbiosis in the 1990s became obstacles on the way of 
further development [12]. Some other East Asian countries, especially those that changed recently the commanding-administrative model of economy to the market economical relations, still have a long way to go transforming their economical and social structure.

Thus, what kind of assumption might be made after comparing the processes of transformations in East Asia in the second part of the XIX - first part of XX cc. and the development of Asian economical crisis in the end of 1990s? It's seems to be reasonable to intend that the colonial expansion of Europeans and subsequent reorganizations did not automatically open in East Asia the doors for the capitalism of the European type. On the contrary, such expansion and reorganizations stimulated great resistance of the East Asian traditional structure. And this resistance was so furious that even now, on the cross of the millennium, its after-effects still make an influence to the East Asian economical and social development. Asian economical crisis in the end of 1990s shows that the processes of transformation of East Asian economical-social reorganization, the beginning of which is dated back to the middle of the last century, are not completed yet. These processes are still going on.

\section{References:}

[1] RBartra. El mood de production Asiatic. Sober Problems de la historian de loss pauses sadistic. .Era: Mexico, 1974. 219 pp.

[2] J.Borrego, A.Bejar, and K.S.Jomo (editors). The Capital, The State, and Late Industrialization Comparative Perspectives On the Pacific Rim (Social Change in Global Perspective). Proceedings of the International Conference, June, 1992, Kuala Lampur, Malaya. West view Press, 1997. 261 pp.

[3] T.Brook. Culture and Economy. The Shaping of Capitalism in Eastern Asia. Ann Arbor: University of Michigan Press, 1997. 304 pp.

[4] C.Christie.A Modern History of Southeast Asia:Decolonization, Nationalism and Separatism. New York, 1996. 213pp. $\mathrm{V}$

[5] R.C.Christopher. The Japanese Mind. Fawcett Books; 1984. 325 $p p$.

[6] M.Clifford. Troubled Tiger: Businessmen, Bureaucrats and Generals in South Korea. M. E. Sharpe Publisher, 1997. 400pp.

[7] M. Elliott. Killing Off Kipling. Newsweek, Vol.CXXX, No. 24, 1997, pp. 14-18.

[8] J.K.Fairbank, E.Reischauer, and A.M.Graig. East Asia: Tradition and Transformation. Houghton Mifflin Co., 1989. 548 pp. 
[9] Hayami Yujiro (editor). The Institutional Foundations of East Asian Economic Development. Proceeding of the International Economic Association Conference Held in Tokyo, Japan, St. Martins Press, 1998.

[10] K.S.Jomo, Tigers in Trouble: Financial Governance And the Crisis in East Asia, Zed Book, 1998.

[11] J.Rowen (editor), Behind East Asian Growth: The Political and Social Foundations of Prosperity, Routledge, 1998.

[12] Sin-Ming Shaw, "Values True and False", Newsweek, No. 24, 1997, p. 21.

[13] Tang Tsou, the Cultural Revolution and Post-Mao Reforms: A Historical Perspective, University of Chicago Press, 1988.

[14] T.Vinood, and P.Stephens, the East Asian Economic Miracle, Washington, the World Bank, 1992.

[15] RWade, Governing the Market: Economic Theory and The Role of Government in East Asian Industrialization) Princeton University Press, 1992.

[16] R.Whitely, Continuity and Change in East Asian Capitalism, Academic Press, 1996. 